\title{
Experimental Evaluation and Characterization of Electron Beam Welding of 2219 AL-Alloy
}

\author{
Mohamed Sobih, ${ }^{1}$ Zuhair Elseddig, ${ }^{2}$ Khalid Almazy, ${ }^{1}$ and Mohamed Sallam ${ }^{1}$ \\ ${ }^{1}$ Military Technical College, Kobry El-Kobbah, Cairo 11766, Egypt \\ ${ }^{2}$ Sudanese Armed Forces, AL Khartoum, Sudan \\ Correspondence should be addressed to Mohamed Sobih; m_sobih@alumni.manchester.ac.uk
}

Received 3 March 2016; Revised 22 June 2016; Accepted 21 July 2016

Academic Editor: Pradeep Lancy Menezes

Copyright (c) 2016 Mohamed Sobih et al. This is an open access article distributed under the Creative Commons Attribution License, which permits unrestricted use, distribution, and reproduction in any medium, provided the original work is properly cited.

\begin{abstract}
Aiming to reduce the weight of components, thus allowing a profit in terms of energy saving, automotive industry as well as aircraft industry extensively uses aluminum alloys. The most widely used joining technology in aircraft industry is riveting, while welding seems to be used in the car industry in the case of aluminum alloys. However, welding technology is characterized by many defects, such as gas porosity; oxide inclusions; solidification cracking (hot tearing); and reduced strength in both the weld and the heat affected zones which could limit its development. Many techniques are used for aluminum alloys welding, among them is electron beam welding (EBW), which has unique advantages over other traditional fusion welding methods due to high-energy density, deep penetration, large depth-to-width ratio, and small heat affected zone. The welding parameters that yield to optimal weld joint have been previously obtained. These optimal parameters were validated by welding a specimen using these parameters. To evaluate this optimal weld joint, complete, microstructural observations and characterization have been carried out using scanning electron microscopy, optical microscopy, and energy dispersive X-ray analysis. This evaluation leads to description and quantification of the solidification process within this weld joint.
\end{abstract}

\section{Introduction}

The desirable chemical, physical, and mechanical properties of aluminum make it the second widely used metal in industry. Additionally it represents an important category of technological materials [1]. Aluminum and its alloys are extensively used in chemical plants and food processing equipment. Certain aluminum copper alloys are used in aircraft while special alloys are used in manufacturing of some automobile parts. One of the most important benefits of using aluminum alloys in automotive industry is that every kilogram of aluminum, which may replace two kilograms of steel, can lead to a net reduction of $10 \mathrm{~kg}$ of $\mathrm{CO}_{2}$ equivalents over the average lifetime of a vehicle [2]. However, there have been challenging weldability problems associated with aluminum alloys to overcome.

Aluminum welding has many difficulties compared with welding of most ferrous alloys in that there are no solidstate phase transformations upon cooling down. Thus, its microstructure is determined by solidification alone. There are, however, a number of problems associated with the welding of aluminum. The features and defects that may contribute to the loss of properties comprise porosity, oxide inclusions, and hot cracking, [3-5].

In addition to fusion welding, several other types of joining techniques are also used and may often be associated with fewer difficulties for producing aluminum joints. These are sold-state welding, for example, friction, resistance, and diffusion welding, as well as brazing and soldering, adhesive bonding, and mechanical joining. Most of these techniques can eliminate the fusion problems because the base metals remain in the solid state during joining. Therefore, they are better than fusion welding in this respect [6]. However, the service conditions may make particular processes unsuitable; for example, for high-temperature applications, soldering and adhesive bonding cannot be candidates, and for leak-tight joints, mechanical joining is not acceptable. Furthermore, the required joint geometry can make friction welding difficult 
to apply. Diffusion welding often provides superior technical benefits for joining small metal parts.

Even though electron beam welding (EBW) is a fusion welding process, it offers chances to reduce or overcome the above-mentioned problems to a certain extent. Therefore, satisfactory joints may be produced. The extreme power density of electron beam (EB) makes joining metals with high melting points possible. Furthermore, the ability to work in a vacuum environment facilitates using the process for welding materials which are extremely reactive at elevated temperature. Consequently, EBW process is widely used in welding aluminum alloy parts, especially in the aerospace industry [7]. EBW process has several controlling parameters. So, improper selection of these parameters may cause defects in the fusion zone (FZ) of weld joint and hence deteriorate the weld mechanical properties. Therefore, the proper selection of the welding process parameters is very essential for obtaining the desired mechanical properties.

In the literature there are few studies on EBW of aluminum and its alloys because of the high capital cost of EBW equipment for academic research. Fujii et al. [8] explained the mechanism of bubble generation when welding 2219 aluminum alloy using electron beam while Dey et al. [9] optimized the weld bead geometry when welding austenitic stainless steel with electron beam; they formulated the constrained optimization problem to minimize weldment area after ensuring the condition of maximum bead penetration. This problem was solved using a binary-coded Genetic Algorithm with a penalty term. The Genetic Algorithm was able to reach near the globally optimal solution. An attempt was made by Chi and Chao [10] to evaluate electron beam weld joints of AZ61A-F extruded plates. They reported that ultimate tensile strength of AZ61A alloy increases with increasing beam current and accelerating voltage, whereas it decreases with increasing welding speed. They also showed in another work [11] that increasing the Al content in AZ series magnesium alloys (up to $10 \%$ ) increases both the strength and the microindentation hardness of the weld and decreases its ductility. Elseddig et al. [12] investigated the effects of beam current, sweep size, welding speed, and focus position on the ultimate tensile strength (UTS) when welding AA1350 aluminum alloy with electron beam. They predicted the optimal combinations of the welding parameters with an objective of maximizing UTS of the weld joint.

This work followed an optimization process using Taguchi method with grey relational analysis to find out the optimal weld bead geometry and mechanical properties of 2219 aluminum alloy [13]. Thus, the objective of this study is to clarify the appropriate welding conditions for good welds. Therefore, specimens were fabricated under optimal condition; these specimens were used to verify the optimal ultimate tensile strength; observe the porosity formation in the weld joint; investigate solidification; and examine the fracture mode of the tensile fracture.

\section{Experimental Procedures}

The specimens used in this investigation were sheets having the dimension $60 \times 50 \times 5 \mathrm{~mm}$ made of 2219 aluminum
TABLE 1: Chemical composition range in wt $\%$ of 2219 alloy.

\begin{tabular}{cccccccc}
\hline \multicolumn{7}{c}{ Element (wt\%) } \\
$\mathrm{Ti}$ & $\mathrm{Mg}$ & $\mathrm{Cu}$ & $\mathrm{Fe}$ & $\mathrm{Si}$ & $\mathrm{Mn}$ & Other & $\mathrm{Al}$ \\
\hline 0.1 & 0.02 & 6.8 & 0.3 & 0.2 & 0.3 & 0.15 & rem \\
\hline
\end{tabular}

rem: remainder.

alloy with the chemical composition tabulated in Table 1 and the following mechanical properties: ultimate tensile strength of $476 \mathrm{MPa}$; $393 \mathrm{MPa}$ yield strength; and $112 \mathrm{BHN}$. Before performing the experiments, the specimens were cleaned to remove the oxide film from their surface. A single-pass weldment of the prepared specimens was conducted using $60 \mathrm{~kW}$ Seo TECH-60 electron beam machine at vacuum of $10^{-5}$ mbar.

The specimens were welded using the optimal parameters obtained from previous study [13]; these parameters are welding speed $10 \mathrm{~mm} / \mathrm{s}$; beam current $18 \mathrm{~mA}$; focus current $909 \mathrm{~mA}$; and sweep size 6 . These parameters lead to maximizing hardness, tensile strength, and penetration depth and minimizing bead width.

After the two plates are welded together, the specimens are sectioned in transverse direction to conduct tensile test, hardness test, and metallographic observations. Specimens for metallographic observation are suitably sectioned, in transverse direction of the welding; the samples were then mechanically polished according to standard metallographic procedures and etched using Keller's regent $(95 \mathrm{~mL}$ water, 2.5 $\mathrm{HNO}_{3}, 1.5 \mathrm{~mL} \mathrm{HCL}$, and $1.0 \mathrm{~mL} \mathrm{HF}$ ) for 10-20 sec. Keller's reagent is extremely hazardous because it contains $\mathrm{HNO}_{3}$ and HF, so great care is required to avoid contact with skin. After etching in Keller's reagent, a macrostructure of welded sample was taken by (SEMMA-202M) scanning electron microscopy at magnification of 50x, and penetration depth and bead width are measured. The metallurgical observations (macrographs) were carried out by optical microscopy and scanning electron microscopy (SEM). X-ray diffraction (XRD) was utilized to determine the different phases that developed in the fusion zone microstructure and base metal. $\mathrm{X}$-ray diffraction was carried out by Xpert Pro machine with the following parameters: accelerating voltage $=40 \mathrm{kv}$; tube current $=20 \mathrm{~mA}$; and diffraction patterns were obtained in the step $2 \theta$ mode in the range of $10-140$ degrees.

\section{Discussions}

The weld joint is characterized by full penetration; $3.51 \mathrm{~mm}$ bead width; hardness $78.7 \mathrm{BHN}$; yield strength of $243 \mathrm{MPa}$; and ultimate tensile strength (UTS) of $295 \mathrm{MPa}$. The obtained UTS represents $62 \%$ of the UTS of the base metal. This result is better than that obtained by Koteswara et al. [14]. They welded the same alloy by Gas Tungsten Arc Welding (GTAW) and reported that a maximum ultimate strength of $268 \mathrm{MPa}$ was obtained when using 2319 with scandium contained as filler material (56\% of the ultimate strength of the base metal). The following subsections evaluate the weld joint in terms of microstructure, solidification mode, heat affected zone (HAZ), FZ structure, and fracture mechanism. 


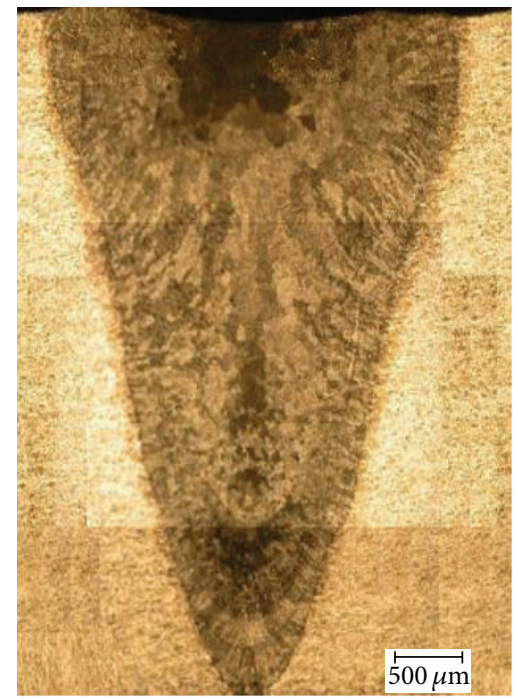

FIGURE 1: Optical macrograph of weld zones for S1.

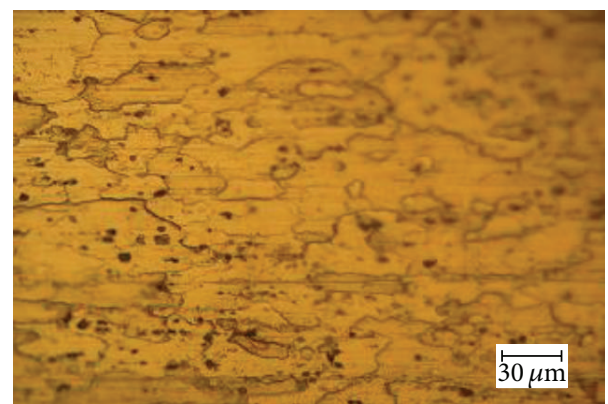

FIGURE 2: Microstructure of the parent material.

3.1. General Characteristic of the Grain Structure in Weld Zones Structure. There are generally four zones which can be characterized from the center line of the bead to the base material: fusion zone; the higher temperature zone known as solution treated; the lower temperature zone near the unaffected base metal known as "overaging"; and the parent material (the unaffected base metal). Figure 1 shows optical macrograph of weld zones for optimal sample; this macrograph reveals that the fusion zone is characterized by columnar dendritic at fusion line and equiaxed coarse grains at weld centerline.

The parent material's grain structure can be seen in Figure 2. It is clear that the microstructure of the parent material consists of elongated grain in the longitudinal direction, as a consequence of deformation introduced during rolling. Moreover, the grain and subgrain were decorated with a fine dispersion of second-phase particles that are most likely $\mathrm{Al}_{2} \mathrm{Cu}$; these precipitates are associated with age hardening developed from Guinier-Preston zone (GPZ) within the grain. This result is confirmed by X-ray diffraction (XRD) analysis, which is discussed later.

3.2. Structure of Fusion Zone. A detailed macrostructure investigation was carried out on the optimal weld to

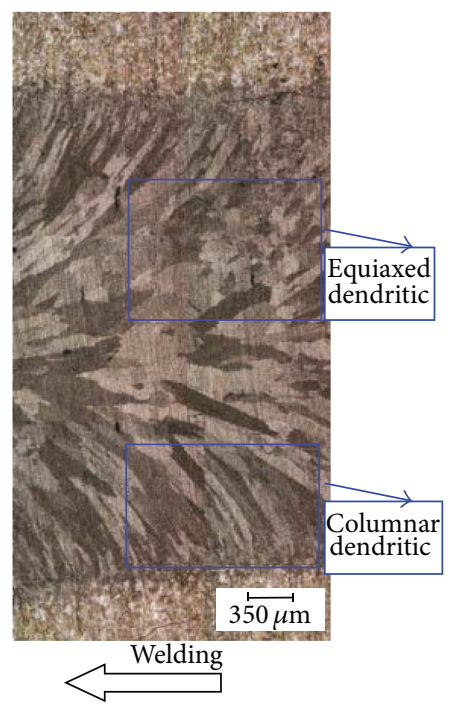

FIGURE 3: Optical macrograph showing plane view of the optimal weld.

understand the solidification characteristic of weld zone. A cross section of the weld is shown in Figure 3; this macrograph illustrates the appearance of the weld zone and the solidification mode in the transverse plane and how the solidification mode changes from columnar dendritic solidification due to preferred directional heat dissipation at fusion line to equiaxed coarse grain solidification at center of the weld due to equal dissipation of heat in all directions. These solidification modes have been reported by a number of researchers for several different materials $[1,15,16]$.

The mode of solidification can be planar, cellular, columnar dendritic, or equiaxed coarse grain. The particular type of solidification that forms depends on the solidification condition and the material system involved. Low under cooling favors cell formation whereas high under cooling favors dendrite formation. At very high under cooling, nucleation will occur ahead of the solid/liquid interface resulting in equiaxed dendrites and grain refinement.

Figure 4 illustrates SEM micrographs of the grain structures that are found at the fusion line. The images are taken from 3 positions: $0.5 \mathrm{~mm}$ below the top of fusion line; at the center of fusion line; and $0.5 \mathrm{~mm}$ above the root of fusion line. The microstructure at the fusion line reveals that the columnar dendritic grows from each base metal grain (epitaxial growth) (Figure 4). Also, the grains at and along the fusion line were observed to be oriented towards the center of the weld without altering their existing crystallographic orientations. Furthermore this direction is perpendicular to pool boundary because this is the direction of the maximum temperature gradient and hence maximum heat extraction.

The microstructure at the center of the fusion zone is characterized by different grain structure from top to root of weld. The region near the top surface of the weld was characterized by equiaxed grains as the solidification rate is equal to welding speed. However, the grain in the center and root was characterized by columnar dendritic (Figure 1). 


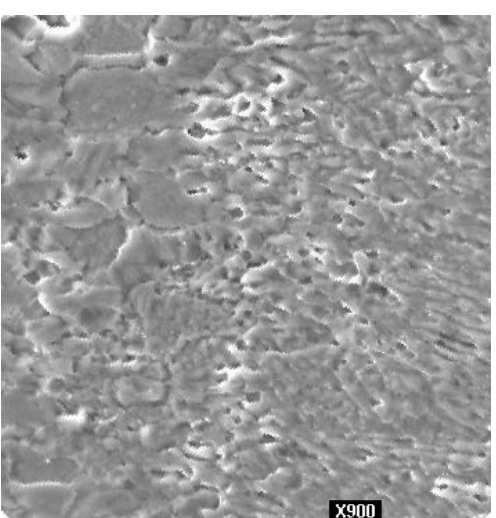

(a)

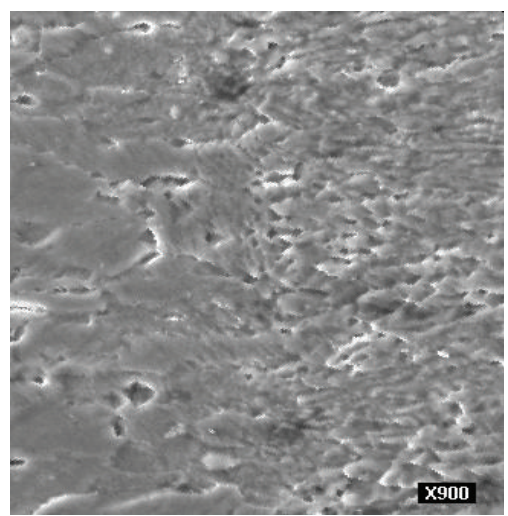

(b)

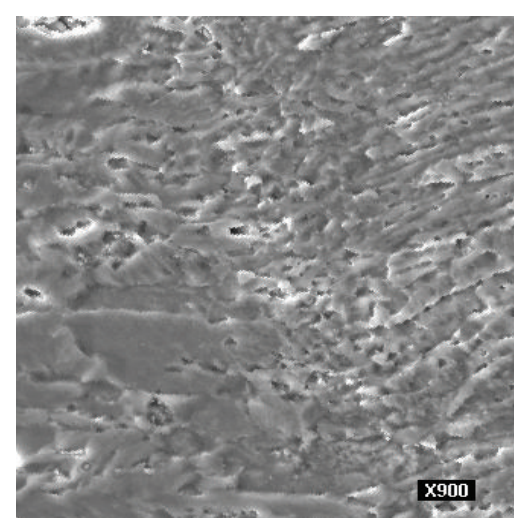

(c)

FIGURE 4: SEM micrograph at different positions in fusion zone line: (a) near the top surface, (b) at the center, and (c) near the root of fusion line.

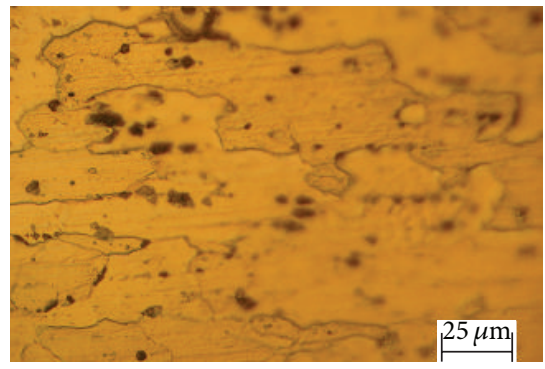

(a)

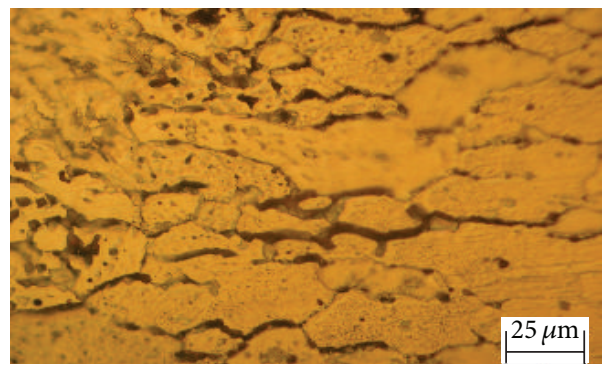

(b)

FIGURE 5: Microstructure of the HAZ indicates (a) overaging zone and (b) solution treated zone.

The nature of solidification as well as welding speed contributes to the formation of the equiaxed grain in the centerline of aluminum alloys weld because increasing welding speed as in the cases of electron beam welding leads to increasing solidification rate.

3.3. Heat Affected Zone Grain Structure. The heat affected zone (Figure 5) is a transition zone between the unaffected base material and the fusion zone; consequently the microstructure of the HAZ varies from the microstructure of typical Al 2xxx series (nearby the BM region) to the microstructure of the solution treated zone in the adjacent of the FZ.

The lower temperature zone near the unaffected base metal known as overaging is shown in Figure 5(a), which indicated that the precipitates grow to such a size that they lose coherency with the matrix. On the other hand, the higher temperature zone near the fusion zone known as solution treated zone is shown in Figure 5(b). Thickening of grain boundaries was observed in this zone which indicated that the precipitate particles are completely dissolved at high temperature, and upon cooling some of these particles precipitate at grain boundaries eliminating the effects of the age hardening and have a detrimental effect on mechanical properties.

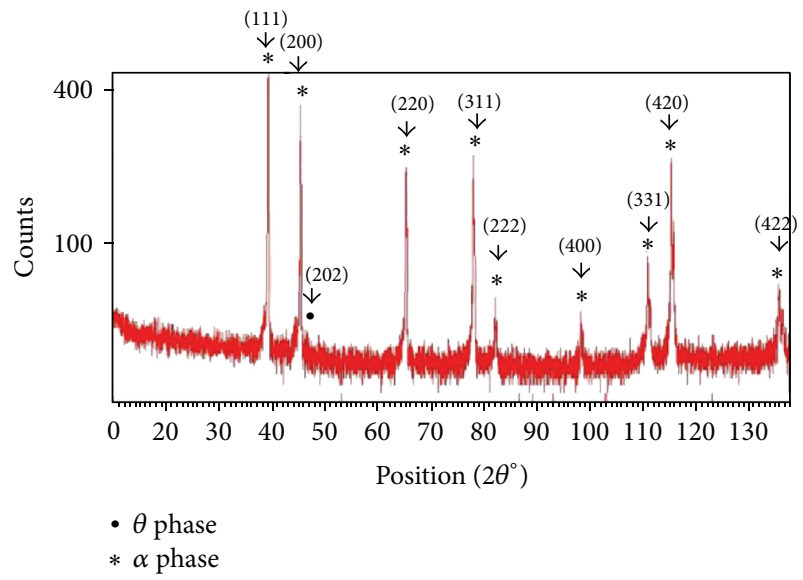

FIGURE 6: X-ray diffraction pattern obtained on the base metal.

3.4. Results of X-Ray Diffraction. Figure 6 illustrates the Xray diffraction (XRD) pattern obtained on the base metal. We can recognize a series of diffraction peaks with the different intensity corresponding to $\alpha$ phase and generated by the constructive interference on different crystallographic planes. The most intense among them are the peaks that appeared at $2 \theta^{\circ}=37.5^{\circ}, 45.5^{\circ}, 65.5^{\circ}, 77.5^{\circ}$, and $117.5^{\circ}$, corresponding to the 


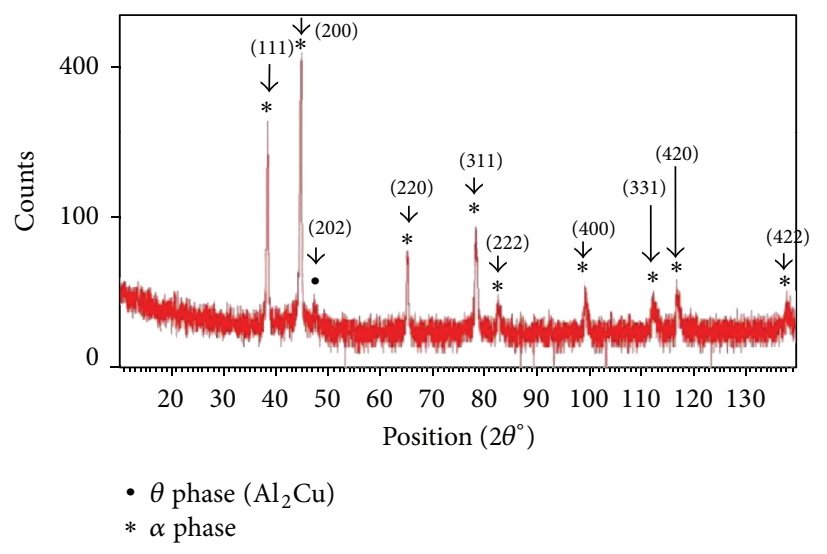

FIgURE 7: X-ray diffraction pattern obtained on the weld.

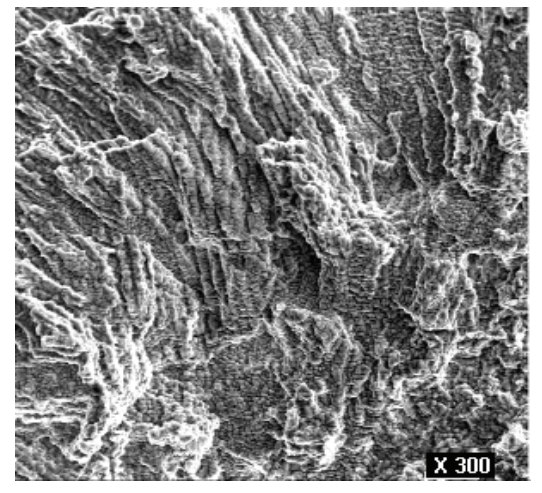

(a)

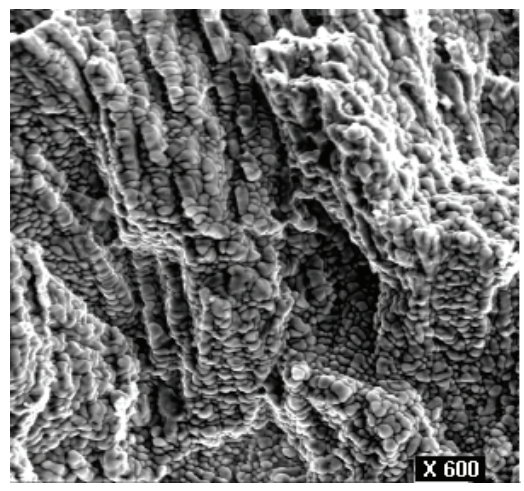

(b)

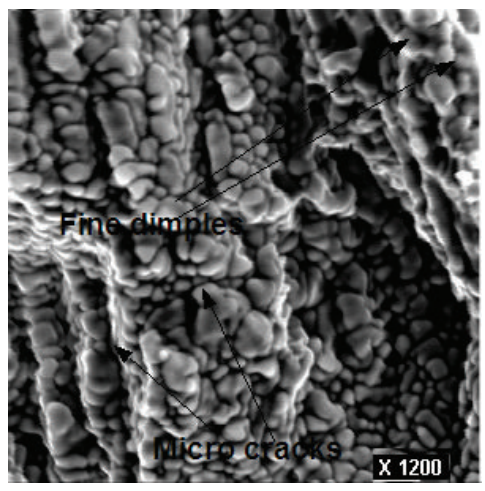

(c)

FIGURE 8: SEM micrograph at the top fracture of weld at different magnification.

diffraction on the crystallographic planes (111), (200), (220), (311), and (420), respectively. Moreover, we can distinguish another diffraction peak appearing at $2 \theta^{\circ}=47.5^{\circ}$, corresponding to the crystallographic plane (202) of the nonequilibrium coherent precipitates $\theta^{\prime}$. This indicates that the base $2219 \mathrm{Al}-$ alloy was subjected to an age hardening heat treatment.

On the other hand Figure 7 presents an XRD pattern obtained on the electron beam welding zone of this alloy. It is noted that the most of the diffraction peaks corresponding to $\alpha$ phase were decreased with a simultaneous increase in the intensity of the peak corresponding to the $\theta^{\prime}$ phase $\mathrm{Al}_{2} \mathrm{Cu}$. This can be explained by the effect of the heat of the weld which can cause overaging in the zones adjacent to the base metal and solution followed by precipitation of the equilibrium $\theta$ phase along the grain boundaries upon cooling in the zones adjacent to the fusion zone.

3.5. Fracture Surface. To understand the fracture mode and to characterize the fracture features, the fracture surfaces of the optimum tensile tested specimen were examined using a scanning electron microscope. SEM micrographs are taken from the top of the weld.

At low magnification (Figure 8), the fracture surface is interdendritic brittle fracture through the weld bead. We can distinguish some areas characterized by the existence of fine dimples indicating ductile fracture mode. Microcracks were observed on the fracture surface; these cracks appear to be along equiaxed grain boundaries. These types of cracks are known as solidification cracks [17]. At higher magnification dimples with various size have been found (Figure 9); fine equiaxed dimples are found in the upper part, while elongated dimples are observed in the lower part.

\section{Conclusions}

An acceptable joint of 2219 aluminum alloy has been obtained by electron beam irradiation. The results show that the electron beam cosmetic pass enables eliminating the undesired surface undercutting of the weld bead.

The characteristics of structures, mechanical properties, and correspondence between mechanical properties and microstructural changes of weld joint were investigated for a specimen welded using optimal welding conditions. From this investigation it is concluded that unique characteristics of the electron beam, namely, small beam diameter, result in a distinguished weld zone with a full penetration depth and small bead width $(3.51 \mathrm{~mm})$. While the rapid heating and cooling rate during electron beam welding result in a small 


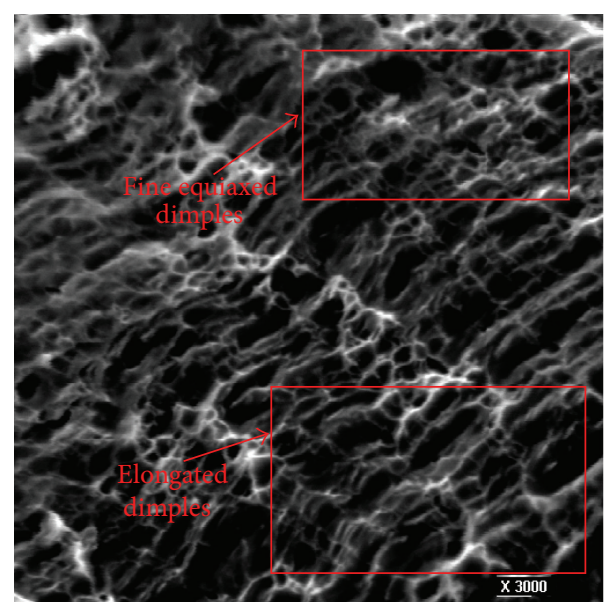

FIGURE 9: Fracture surfaces at high magnification.

HAZ, consequently an acceptable ultimate tensile strength of $295 \mathrm{MPa}$ (represents $62 \%$ of the ultimate tensile strength of the base metal) is obtained. This reduction in tensile strength is believed to be a result of the solidification cracks that appeared in the SEM of the fracture surfaces of the optimum tensile tested specimen.

\section{Competing Interests}

The authors declare that they have no competing interests.

\section{References}

[1] E. George and G. E. Totten, Eds., Handbook of Aluminum, Volume 1: Physical Metallurgy and Processes, Marcel Dekker, New York, NY, USA, 2003.

[2] S. Toros, F. Ozturk, and I. Kacar, "Review of warm forming of aluminum-magnesium alloys," Journal of Materials Processing Technology, vol. 207, no. 1-3, pp. 1-12, 2008.

[3] G. Mathers, The Welding of Aluminum and Its Alloys, Woodhead, Cambridge, UK, 2002.

[4] G. E. Totten and D. S. MacKenzie, Handbook of Aluminum: Physical Metallurgy and Processes, vol. 1, Marcel Dekker, New York, NY, USA, 2003.

[5] J. F. Lancaster, Metallurgy of Welding, Woodhead, Cambridge, UK, 6th edition, 1999.

[6] W. H. Kearns, Welding Handbook, American Welding Society, 1997.

[7] G. F. Benedict, Nontraditional Manufacturing Processes, Marcel Dekker, New York, NY, USA, 1st edition, 1987.

[8] H. Fujii, H. Umakoshi, Y. Aoki, and K. Nogi, "Bubble formation in aluminium alloy during electron beam welding," Journal of Materials Processing Technology, vol. 155-156, no. 1-3, pp. 12521255, 2004.

[9] V. Dey, D. K. Pratihar, G. L. Datta, M. N. Jha, T. K. Saha, and A. V. Bapat, "Optimization of bead geometry in electron beam welding using a genetic algorithm," Journal of Materials Processing Technology, vol. 209, no. 3, pp. 1151-1157, 2009.

[10] C.-T. Chi and C.-G. Chao, "Optimum evaluation for electron beam weldments of AZ61A-F extruded plates," Welding Journal, vol. 86, no. 5, p. 113s, 2007.
[11] C.-T. Chi, C.-G. Chao, T.-F. Liu, and C.-C. Wang, "A study of weldability and fracture modes in electron beam weldments of AZ series magnesium alloys," Materials Science and Engineering A, vol. 435-436, pp. 672-680, 2006.

[12] Z. A. Elseddig, M. Sobih, Kh. Almazy, and M. Sallam, "Experimental investigation of electron beam welding of AA1350 aluminum alloy," in Proceedings of the in 14th International Conference on Applied Mechanics and Mechanical Engineering, Cairo, Egypt, 2010.

[13] M. Sobih, Z. Elseddig, K. Almazy, A. Youssef, and M. Sallam, "Optimization of EBW parameters for 2219 al-alloy using grey relation method," Advanced Materials Research, vol. 591-593, pp. 507-514, 2012.

[14] S. R. Koteswara, G. M. Reddy, K. S. Rao, P. S. Rao, M. Kamaraj, and K. P. Rao, "Gas tungsten arc welded AA 2219 alloy using scandium containing fillers mechanical and corrosion behavior," Transactions of the Indian Institute of Metals, vol. 57, no. 5, pp. 451-459, 2004.

[15] A. Kostrivas and J. C. Lippold, "A method for studding weld fusion boundary microstructure evaluation in aluminum alloys," Welding Journal, vol. 79, no. 1, pp. 1s-8s, 2000.

[16] S. Kou, Welding Metallurgy, John Wiley \& Sons, 2003.

[17] F. M. Ghaini, M. Sheikhi, M. J. Torkamany, and J. Sabbaghzadeh, "The relation between liquation and solidification cracks in pulsed laser welding of 2024 aluminium alloy," Materials Science and Engineering: A, vol. 519, no. 1-2, pp. 167-171, 2009. 

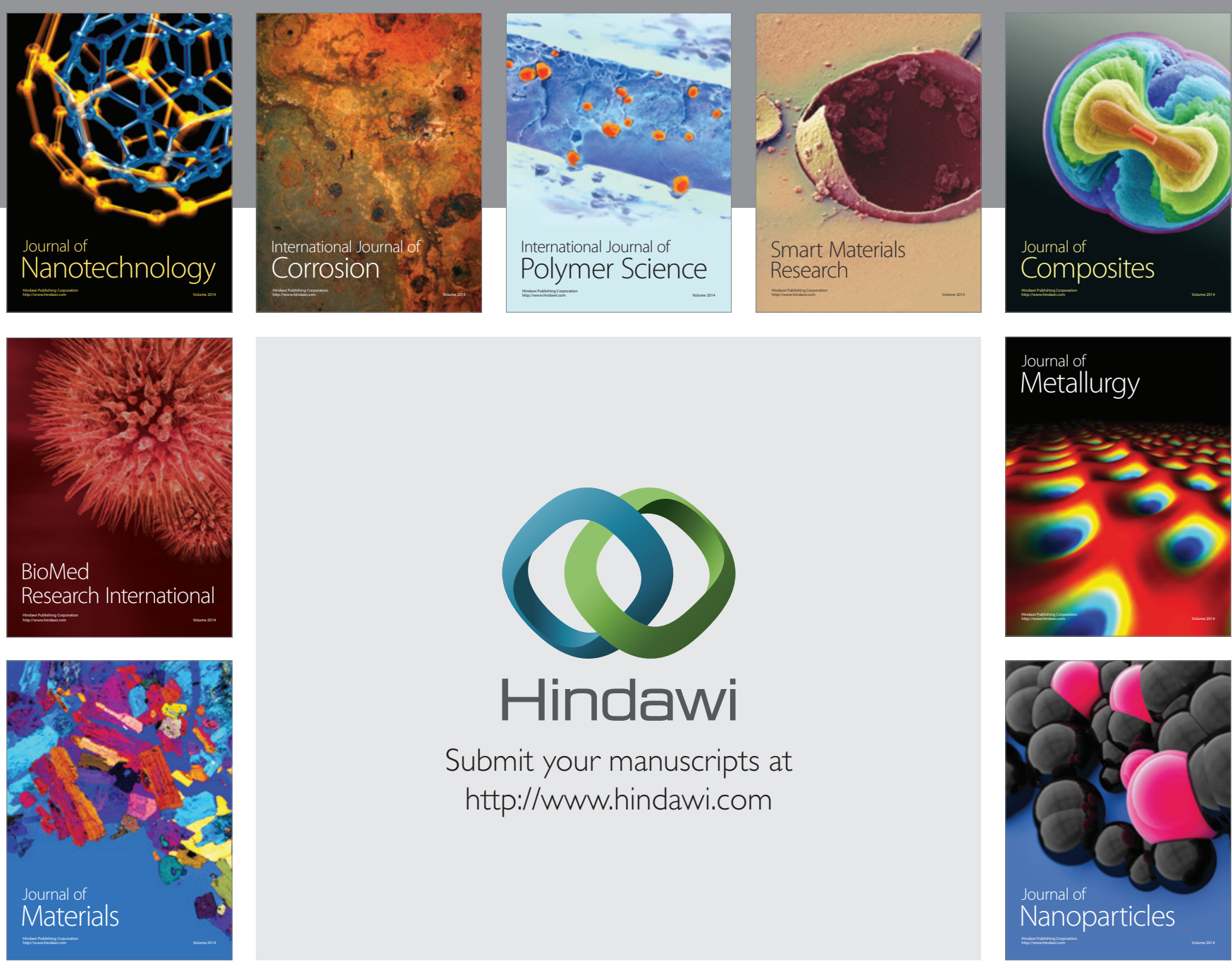

\section{Hindawi}

Submit your manuscripts at

http://www.hindawi.com

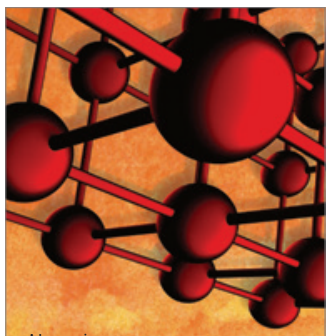

Materials Science and Engineering
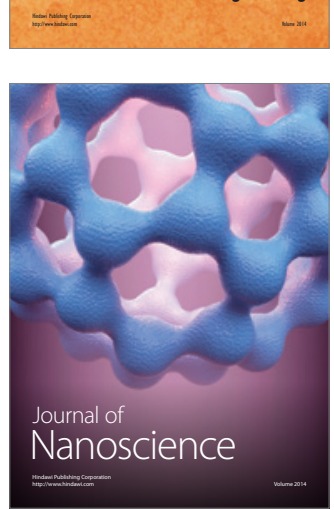
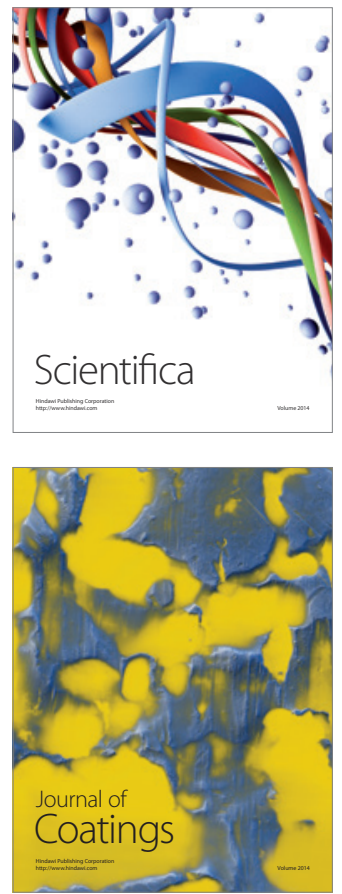
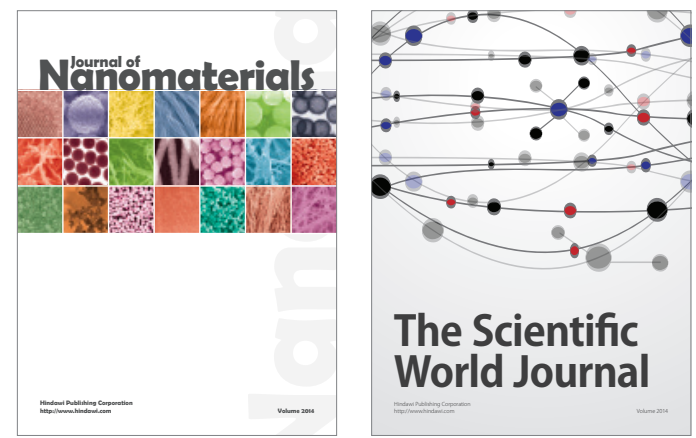

The Scientific World Journal
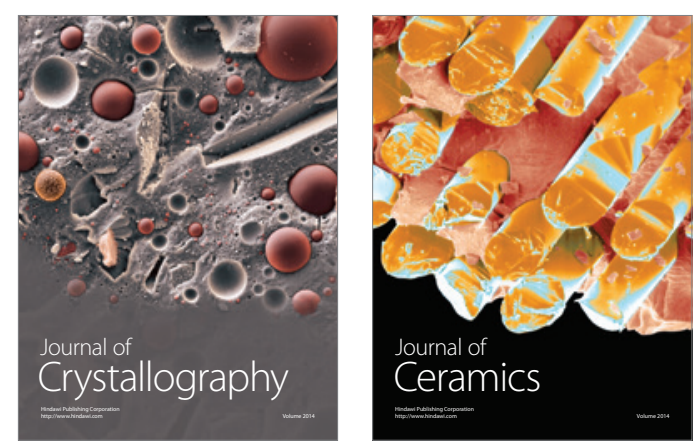
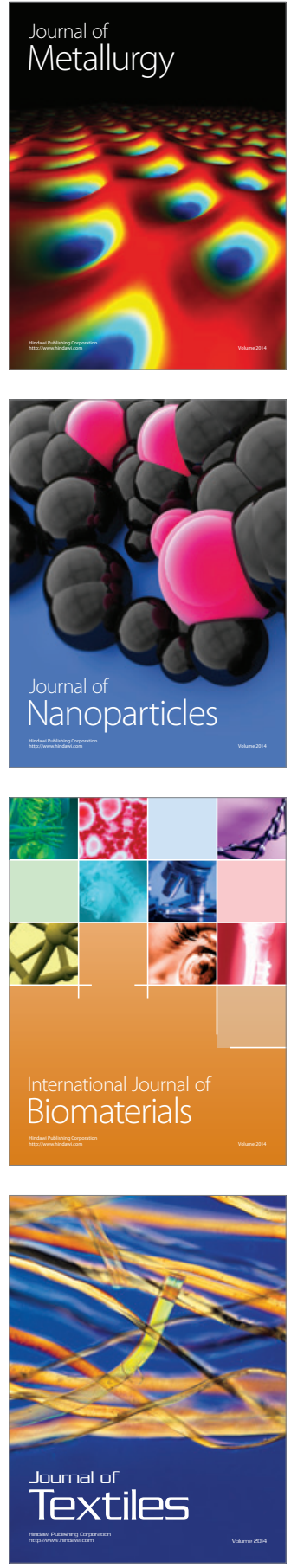